2016-09

\title{
Steps to prevent SUDEP: the validity of risk factors in the SUDEP and seizure safety checklist: a case control study
}

Shankar, Rohit

http://hdl.handle.net/10026.1/11649

10.1007/s00415-016-8203-3

Journal of Neurology

Springer Science and Business Media LLC

All content in PEARL is protected by copyright law. Author manuscripts are made available in accordance with publisher policies. Please cite only the published version using the details provided on the item record or document. In the absence of an open licence (e.g. Creative Commons), permissions for further reuse of content should be sought from the publisher or author. 
Steps to prevent SUDEP: the validity of risk factors in the SUDEP and seizure safety checklist: a case control study

Rohit Shankar, Matthew Walker, Brendan McLean, Richard Laugharne, Fucundo Ferrand, Jane Hanna \& Craig Newman

\section{Journal of Neurology}

ISSN 0340-5354

J Neurol

DOI 10.1007/s00415-016-8203-3

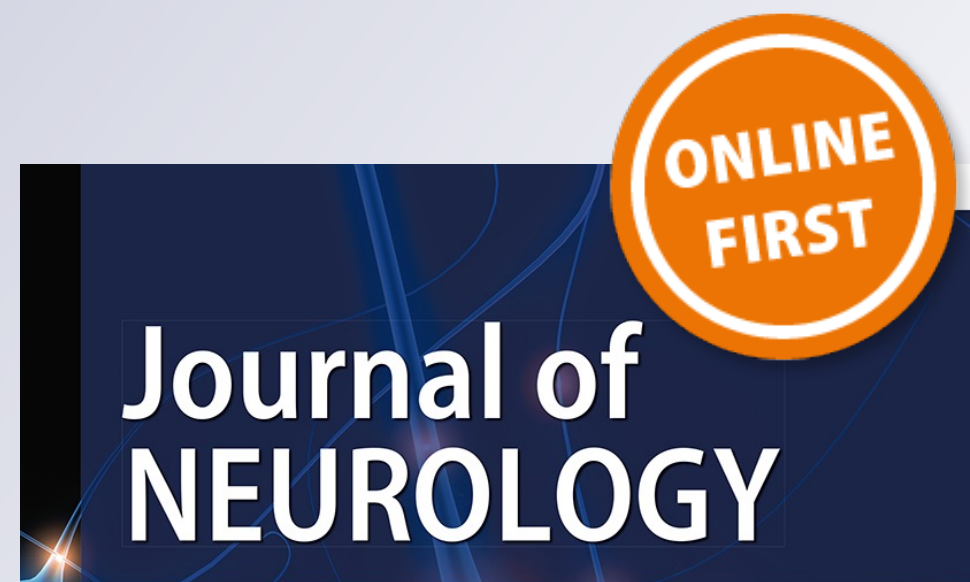

Joint Chief Editors

R. A. Barker, Cambridge

M. Filippi, Milan

M. Strupp, Munich

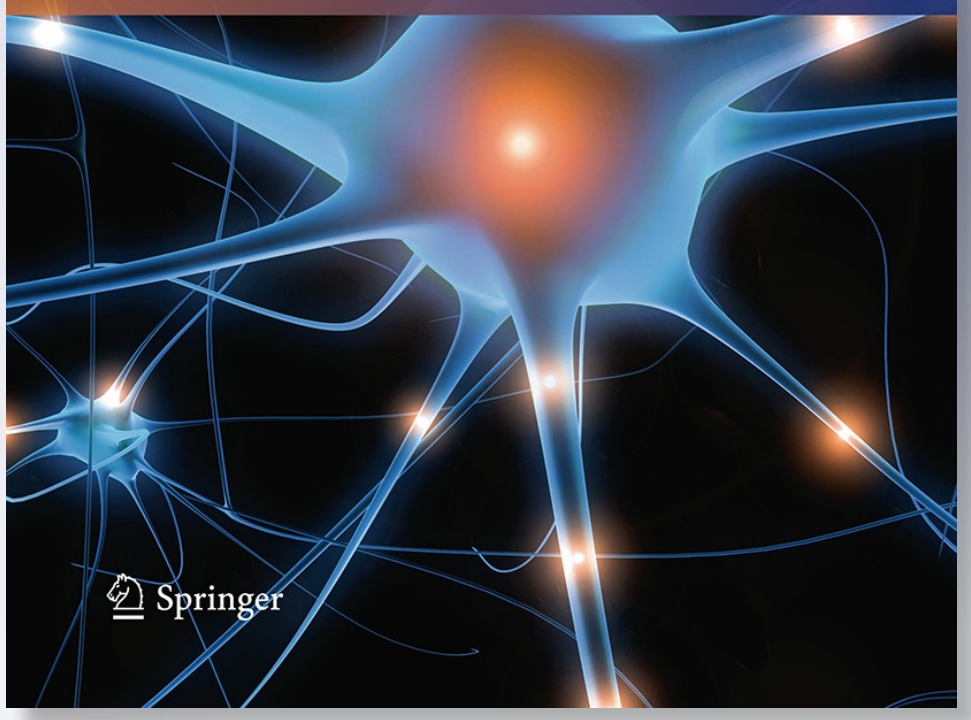

算 Springer 
Your article is protected by copyright and all rights are held exclusively by SpringerVerlag Berlin Heidelberg. This e-offprint is for personal use only and shall not be selfarchived in electronic repositories. If you wish to self-archive your article, please use the accepted manuscript version for posting on your own website. You may further deposit the accepted manuscript version in any repository, provided it is only made publicly available 12 months after official publication or later and provided acknowledgement is given to the original source of publication and a link is inserted to the published article on Springer's website. The link must be accompanied by the following text: "The final publication is available at link.springer.com". 


\title{
Steps to prevent SUDEP: the validity of risk factors in the SUDEP and seizure safety checklist: a case control study
}

\author{
Rohit Shankar ${ }^{1,6} \cdot$ Matthew Walker $^{2} \cdot$ Brendan McLean $^{3} \cdot$ Richard Laugharne $^{1,6}$ • \\ Fucundo Ferrand $^{1} \cdot$ Jane Hanna ${ }^{4} \cdot$ Craig Newman $^{5}$
}

Received: 16 April 2016/Revised: 24 May 2016/Accepted: 10 June 2016

(c) Springer-Verlag Berlin Heidelberg 2016

\begin{abstract}
Our objectives were to compare people with epilepsy (PWE) who died of sudden unexpected death in epilepsy (SUDEP) with live controls using the risk factor items of the SUDEP and Seizure Safety Checklist. All 48 SUDEPs of 93 epilepsy deaths which occurred in Cornwall UK 2004-2012 were compared to 220 live controls using the SUDEP and Seizure Safety Checklist, an evidenced based tool used to communicate person centered risk of SUDEP to PWE. The odds ratio for having a specific factor in those who died was compared to controls and ranked according to $P$ value using a sequential Bonferroni correction for multiple comparisons. Of the 17 modifiable and non-modifiable risk factors analyzed 9 were statistically significant of which 7 are potentially modifiable. Well known modifiable factors such as nocturnal monitoring, compliance and sleeping position featured prominently in the risk association. This is the first case control study exploring the risk factors for SUDEP since 2009. The findings are compared to the current considered risk factors as identified in a major recent review. The study further validates certain SUDEP risk factors. It highlights that the majority of risk factors strongly associated with SUDEP
\end{abstract}

Rohit Shankar

Rohit.shankar@nhs.net

1 Cornwall Partnership NHS Foundation Trust, Chygovenck Threemilestone Industrial Estate Highertown, Truro, Cornwall TR4 9LD, UK

2 UCL Institute of Neurology, London, UK

3 Royal Cornwall Hospital Trusts, Truro, UK

4 SUDEP Action, Oxfordshire, UK

5 Plymouth University, Plymouth, England

6 Exeter Medical School, Exeter, England are potentially modifiable. There is an emerging profile to rank the risk factors. It furthers the evidence to use structured risk assessment and communication tools such as the SUDEP and Seizure Safety Checklist in daily clinical practice. It highlights key areas for a person centered discussion to empower PWE to mitigate risk.

Keywords SUDEP · Case-control study · Risk factors · Epilepsy deaths

\section{Introduction}

Sudden unexpected death in epilepsy (SUDEP) is the most important direct cause of deaths in epilepsy [1]. People with epilepsy (PWE) are 20 times more likely to die suddenly compared to the general population [2]. SUDEP is the most common cause of death in PWE. In the UK in 2013, 1187 people died from epilepsy (includes SUDEP, status, etc.), roughly the same amount of that died from asthma (1255) despite there being a population of over 5.3 million people with asthma while PWE number around 600,000. The 2013 Office of National Statistics UK data suggest that up to $60.5 \%$ of these epilepsy deaths were seen as avoidable, whereas $25.5 \%$ of asthma deaths were. This suggests that there may be improvement in the way we identify risk and manage PWE in the community.

In the recent literature review on risk factors for SUDEP [3], 20 factors were identified that increased the risk of SUDEP. These 20 factors were subsequently applied to a previously unexposed set of all SUDEPs $(n=48)$ extracted by going through all epilepsy deaths $(n=93)$ in the county of Cornwall UK (population 550,000) between 2004 and 2012 to see if they remained consistent with the literature review findings [4]. It was found that 17 factors 
remained well associated with SUDEP and are directly relevant for people living with epilepsy. These 17 factors forms the background of the seizure and SUDEP safety checklist, a 10 min risk assessment tool used in epilepsy clinics across UK and the self-monitoring of epilepsy risk mobile app for smart phones in both android and Apple, EpSMon [5-7]. We compared these 17 factors between the 48 subjects who died from SUDEP in Cornwall with 220 of 231 continuous patients living with epilepsy who attended local outpatient epilepsy clinics to determine how strongly these factors are associated with SUDEP risk in a welldefined population.

\section{Method}

We compared data collected over nine continuous years of SUDEPs at the Cornwall Coroner's office using the SUDEP and Seizure Safety Checklist [3, 4] with data from medical records of clinical discussion with a full year of most PWE attending local epilepsy outpatient clinics on the potential risk factors identified for SUDEP using the same checklist.

We systemically inspected all epilepsy and epilepsy associated deaths which occurred in Cornwall between 2004 and 2012 all made available to us by the HM Cornwall coroner. These are the deaths where epilepsy was a primary or a secondary cause. The Cornwall coroner's office has a computerized system with a search engine to explore all registered death certificates. The data were collected from the coroner's records using the terms 'ep', 'epilepsy', 'seizures', 'fits', 'sudden death' and 'SUDEP' in either part 1 or 2 of the death certificate. Ninety-three deaths were thus identified by the coroner's office. Each death's case file which included all comprehensive medical records up to the point of death was reviewed to ascertain those deaths which met the SUDEP criteria and classification using the operational definition of SUDEP provided by Nashef and Anneger [4, 8]. Of the 93 cases of epilepsy-related deaths which occurred in Cornwall between 2004 and 2012, forty eight cases met the criteria for SUDEP. We cross-referenced the epilepsy deaths of these years (2004-2012) with public health data on epilepsy deaths held by the Public Health Department of Cornwall. The public health data showed 73 epilepsy deaths (43 male and 30 females) for the period of 2006-2012. This is in keeping with our estimates for that period. The public health data only had the year, number of deaths and sex recorded. We then applied the clinical risk factors of the SUDEP and Seizure Safety Checklist to all the SUDEP deaths. The detailed definitions used for the risk factors are described in previous papers $[3,4,6]$ and Table 1.
The control population attended two specialist epilepsy outpatient clinics in Cornwall and for whom the seizure safety and SUDEP checklist [3, 5-7] was administered as part of routine clinical practice over 1 year. The population was a continuous sample. Of 231 attendees in the 1 year (05/2013-05/2014) to the two clinics. Two hundred and twenty consented to the use of the checklist. One year was chosen to sample the whole clinic population as maximum follow up time is 1 year.

We calculated the odds ratio for having a specific factor in those who died from SUDEP compared to controls. We ranked the factors according to $P$ value and used a sequential Bonferroni to correct for multiple comparisons. Low numbers and missing data prevented a logistic regression analysis.

\section{Results}

The United Kingdom (UK) has a population of about 60 million. Cornwall is a county in UK with a population of 600,000 (about $1 \%$ of the UK population). It is largely a rural county and not subject to major immigration/emigration (except for large number of tourists during summer). The incidence of SUDEP has been estimated as $0.1 \%$ of all people diagnosed with epilepsy per year though it can raise to 1 in 150 PWE in refractory cases. An estimated 600 deaths occur in a year due to SUDEP in the UK, and thus Cornwall would be expected to have approximately six SUDEP deaths a year. Our study is consistent with these numbers as 48 deaths over 9 years represent a rate of 5.33 SUDEP deaths/year.

Our case sample was 48 people, 33 male and 15 female who died from SUDEP in Cornwall UK over the 9 year period [4]. Among the 48 deaths, the mean age was 42.5 years and median 42 years with a range of 2-82 years. Our control sample was 220 outpatients attending epilepsy clinics within Cornwall of whom 115 were male and 105 female. Among the 220 people, the mean age was 42.76 years and median 47.5 years with a range of 9-86 years. The majority of the SUDEP cases had been known to the local specialist epilepsy services sometime in their lifetime. However, $80 \%$ of the SUDEP cases did not see a specialist in the year prior to death.

The comparison between the groups is given in Table 1 and illustrated in Fig. 1. Of the 17 risk factors, nine showed a significant difference between the two groups. Two significant risk factors-duration of epilepsy and diagnosis of generalized tonic-clonic epilepsy-are not modifiable. However, there were seven potentially modifiable risk factors: unclear treatment history, poor adherence to medication, subtherapeutic medication levels, alcohol misuse, no night surveillance, sleeping in the prone 
Table 1 Univariate analysis

\begin{tabular}{ll}
\hline Rank & Factor and its description \\
\hline 1 & Sleeping in prone position \\
Independent risk factor evidenced by several studies including a systematic \\
review \\
The prone position is defined as lying on the belly, chest, or face, with or \\
without obstruction of the nose or mouth. Sleeping in the prone position or \\
remaining in a prone position post seizure is considered a risk
\end{tabular}

2 Treatment history-unclear

0.03

Odds ratio

$95 \% \mathrm{CI}$

$P$ value

This is defined as where the rationale for treatment in the last 6 months is not 0.034

$0.012,0.094$

$<0.001 *$ supported by current clinical evidence base such as NICE. For example not modifying AED treatment if someone has refractory epilepsy or not considering referring to a comprehensive epilepsy center for a surgical evaluation

$3 \quad$ Generalized tonic-clonic epilepsy

$0.01,0.09$

Combined data from the previous four case-control studies found this is the most important risk factor

$4 \quad$ Increasing seizure frequency

Active seizures which in the last 6 months were noted to worsen in frequency of $>25 \%$

$5 \quad$ Compliance issues

$0.03,0.23$

$<0.001^{*}$

This factor is defined by finding of variable AED hair strand levels in SUDEP group. Compliance issues were also assessed via patient reporting as evidenced by medical records in both groups. Adherence issues (including not picking up prescriptions) found as a factor across all epilepsy-related deaths as increasing risk by $50 \%$

$6 \quad$ Alcohol problem

$0.04,0.28$

$<0.001^{*}$

Is defined as where there is a clinically definable alcohol disorder as identified by the WHO ICD 10 diagnostic Manual. A systematic analysis of epilepsy deaths confirmed this risk factor

$7 \quad$ Subtherapeutic AED levels

$0.025,0.24$

$<0.001^{*}$

Is a finding linked closely to compliance

Nocturnal seizures were shown to have a 4 fold increased risk. $60 \%$ of all SUDEPs in large control study. Nocturnal surveillance thus where present is considered to be a protective factor

$9 \quad$ Duration ( $>15$ years)

This has been suggested by several studies, but not after multiple logistical regression analysis for seizure frequency

10 Early onset epilepsy

Where the onset of epilepsy is before the age of 15 years

11 Frequent AED changes

This is defined as where the changes of dose or medication were not following British National Formulary (BNF) guidance on titration in the last 6 months

This is defined as having 'anxiolytic medication' as defined by BNF 4.1.2

Currently it is unclear how relevant a risk factor this is as it has not been clearly defined

Two case-control studies found ID to be a risk factor whereas two others did not. In the combined analysis ID was not a significant risk factor The incidence of SUDEP was higher among children with "complicated" epilepsy (with known structural brain lesion, intellectual disability) than those without. Concerns exist on the way ID is described and cases collected 
Table 1 continued

\begin{tabular}{|c|c|c|c|c|}
\hline Rank & Factor and its description & Odds ratio & $95 \% \mathrm{CI}$ & $P$ value \\
\hline 14 & $\begin{array}{l}\text { Male gender } \\
\text { Was found a risk factor commonly in descriptive studies but has not been } \\
\text { replicated in controlled studies }\end{array}$ & 0.62 & $0.29,1.31$ & 0.21 \\
\hline 15 & $\begin{array}{l}\text { Depression treatment } \\
\text { This is defined as having clinical depression as per ICD 10/DSMV and/or } \\
\text { being on antidepressant medication' as defined by BNF } 4.3 \text { and/or having } \\
\text { therapy/counseling for depression } \\
\text { Currently it is unclear how relevant a risk or a safety factor depression or its } \\
\text { treatment particularly SSRIs are. This is has not been clearly defined }\end{array}$ & 0.74 & $0.31,1.80$ & 0.50 \\
\hline 16 & $\begin{array}{l}\text { Carbamazepine } \\
\text { There is no significant association between use of carbamazepine and } \\
\text { SUDEP risk as per current evidence }\end{array}$ & 1.10 & $0.51,2.32$ & 0.83 \\
\hline 17 & $\begin{array}{l}\text { Increasing seizure severity } \\
\text { This is evidenced by an increase in the last } 6 \text { months of the administration of } \\
\text { rescue medication such as Midazolam, paramedic call outs or ED visits as } \\
\text { recorded in clinical notes }\end{array}$ & 0.94 & $0.26,3.40$ & 0.92 \\
\hline
\end{tabular}

Factors are ranked by $P$ value. * indicates significant using a sequential Bonferroni correction for multiple comparisons with alpha $=0.05$

Fig. 1 Odds ratios for having SUDEP given risk factor. Bars represent $95 \%$ CI. Solid circles are significant factors after sequential Bonferroni correction

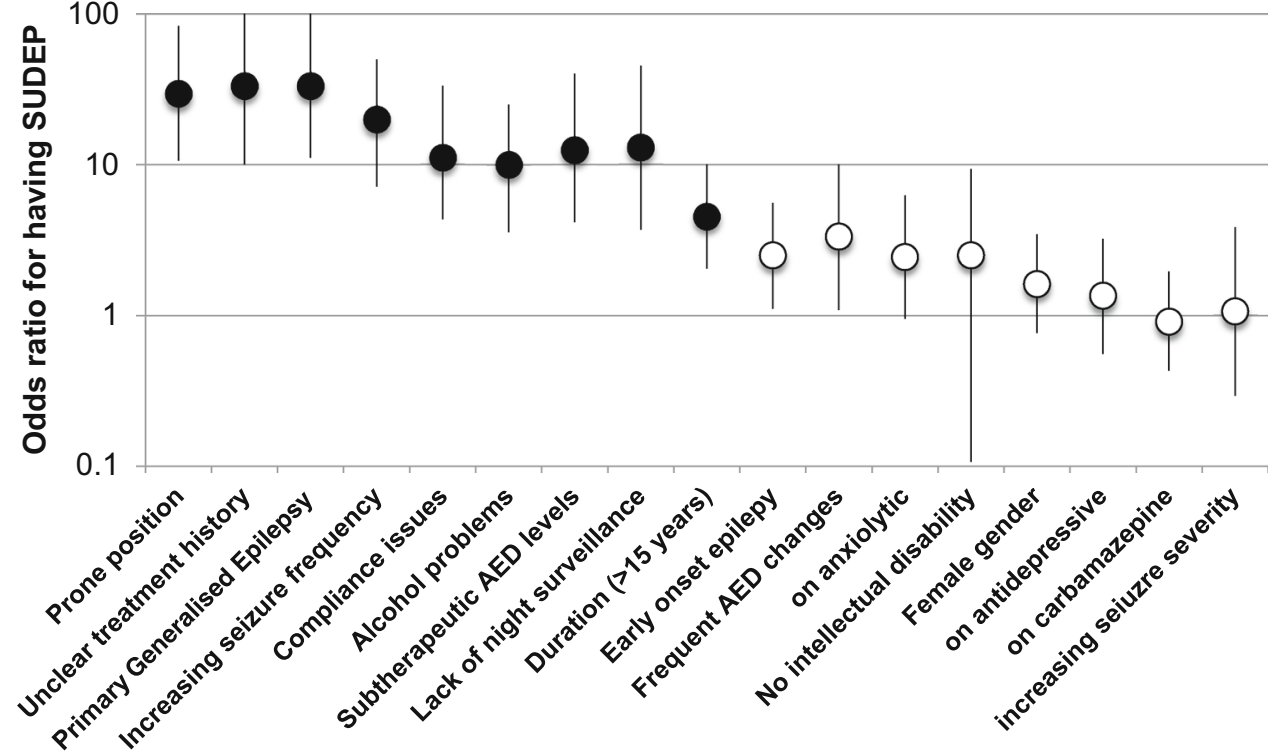

position and increasing seizure frequency, which could be ranked.

\section{Conclusion}

This is the first case-control study exploring the risk factors for SUDEP since 2009. There were four major case control studies looking at SUDEP risk factors [9-13] whose data was pooled and a combined analysis of the identified risk factors conducted in 2011 [9]. Our study supports many of the pooled findings from those studies that certain factors have a considerable impact upon the risk of SUDEP, and importantly, a large proportion of these factors can be modified. Some factors considered are new or are bearing different results to the pooled analysis. This study finding has been compared to the current evidence of a recent major review on SUDEP risk factors (Table 2).

The four case control studies [10-13] while all trying to enumerate risk factors were diverse in their design, examination of population of risk and controls (Table 3). Risk factor examination was more explorative in nature. The pooled analysis [9] was a function of the results of these studies. Our study unlike other SUDEP case control 
Table 2 Comparison between identified risk factors in the study and recently published review of risk factors for SUDEP

\begin{tabular}{lll}
\hline Risk factor & Shankar et al. findings & Tomson et al. [17, 18] review of risk factors \\
\hline Sleeping in prone position & Significant & A risk factor requires more confirmation \\
Treatment history-unclear & Significant & Not considered in review \\
Generalized tonic-clonic epilepsy & Significant & Strong risk factor \\
Increasing seizure frequency & Significant & A risk factor \\
Compliance issues & Significant & Possible risk factor \\
Alcohol problem & Significant & Possible risk factor \\
Subtherapeutic AED levels & Significant & Unreliable as a risk factor \\
Night surveillance & Significant & A risk factor but requires more confirmation \\
Duration (>15 years) & Significant & A risk factor \\
Early onset epilepsy & Close to significant-power might play a role & A risk factor \\
Frequent AED changes & Close to significant-power may play a role & Not considered in review \\
Presence of anxiolytic medication & Close to significant-power may play a role & Not considered in review \\
Intellectual disability (ID) & Not significant-confounder recognized & Conflicting evidence on risk factor. Require more studies \\
Male gender & Not significant & A risk factor \\
Depression treatment & Not significant & Not considered in review \\
Carbamazepine & Not significant & Not a risk factor \\
Increasing seizure severity & Not significant & Not considered in review \\
\hline
\end{tabular}

Table 3 Details extracted from the pooled analysis study [9]

\begin{tabular}{|c|c|c|c|c|c|}
\hline & $\begin{array}{l}\text { US study } \\
{[10]}\end{array}$ & Swedish study [13] & Scottish study [12] & English study [11] & Our study \\
\hline $\begin{array}{l}\text { Rough time } \\
\text { period of } \\
\text { study }\end{array}$ & 1991-1996 & 1980-1989 & $\begin{array}{l}\text { From } 1982 \text { all deaths till } \\
\text { near the study }(2007)\end{array}$ & 1989-1998 & 2004-2012 \\
\hline $\begin{array}{l}\text { Case to } \\
\text { controls mix }\end{array}$ & $\begin{array}{l}20 \text { cases } \\
\text { and } 80 \\
\text { controls }\end{array}$ & $\begin{array}{l}56 \text { cases and } \\
157 \text { controls }\end{array}$ & $\begin{array}{l}64 \text { cases and } \\
119 \text { controls }\end{array}$ & $\begin{array}{l}149 \text { cases and } \\
602 \text { controls }\end{array}$ & $\begin{array}{l}48 \text { cases and } 220 \\
\text { controls }\end{array}$ \\
\hline $\begin{array}{l}\text { Case } \\
\text { description }\end{array}$ & $\begin{array}{l}\text { SUDEP in } \\
\text { specialist } \\
\text { epilepsy } \\
\text { centers }\end{array}$ & $\begin{array}{l}\text { Discharged from hospitals } \\
\text { diagnosis of epilepsy on } \\
\text { death certificates }\end{array}$ & $\begin{array}{l}\text { Those registered with the } \\
\text { epilepsy unit }\end{array}$ & $\begin{array}{l}\text { SUDEP were identified by } \\
\text { coroners, neurologists, } \\
\text { self-referred by family } \\
\text { members, and by the } \\
\text { charity Epilepsy } \\
\text { Bereaved }\end{array}$ & $\begin{array}{l}\text { SUDEP in community } \\
\text { and being } \\
\text { representative of all } \\
\text { deaths in Cornwall } \\
\text { UK (pop: } 600,000 \text { ) }\end{array}$ \\
\hline Case specifics & & $\begin{array}{l}\text { Identified deaths between } \\
15 \text { and } 70 \text { years }\end{array}$ & & $16-50$ years & No age limit \\
\hline $\begin{array}{l}\text { Control } \\
\text { description }\end{array}$ & $\begin{array}{l}\text { Controls } \\
\text { randomly } \\
\text { selected }\end{array}$ & $\begin{array}{l}\text { For each case of SUDEP } 3 \\
\text { living controls were } \\
\text { randomly drawn from } \\
\text { the study population and } \\
\text { matched on year of birth, } \\
\text { sex, and assessment } \\
\text { period }\end{array}$ & $\begin{array}{l}2 \text { living controls were } \\
\text { randomly selected from } \\
\text { the Epilepsy Unit } \\
\text { population and matched } \\
\text { on year of birth, gender, } \\
\text { and syndrome } \\
\text { classification }\end{array}$ & $\begin{array}{l}4 \text { controls with epilepsy } \\
\text { were randomly selected } \\
\text { from a diagnostic index } \\
\text { and a prescription } \\
\text { database and matched to } \\
\text { each SUDEP case } \\
\text { according to age and } \\
\text { geographic location }\end{array}$ & $\begin{array}{l}\text { The control population } \\
\text { attended two specialist } \\
\text { epilepsy outpatient } \\
\text { clinics in Cornwall. } \\
\text { The population was a } \\
\text { continuous sample }\end{array}$ \\
\hline
\end{tabular}

studies had a pre-designed questionnaire which had the advantage of having extracted the risk factors of all the other studies, in particular, the pooled analysis [9] and re- testing it in a new population thus looking to see if the factors identified by the pooled analysis were generally applicable. The pooled analysis got its data from studies of 
different geographic regions and demographics. The current study observed if such a pooled result could be representative in a new region with a well-defined population.

There are other advantages to our study too. Three of the four past studies $[10,12,13]$ were hospital centric with the deaths being traced from hospital records and not community based. One of the four studies [11] collected referrals from diverse streams but was not structured to identify the full population at risk, and thus not systematic. Our study has the advantage that controls and SUDEP were drawn from the same population. Moreover, it is also the only study where a pre-developed checklist has been used in both the people who died and controls.

Poor accessibility of services or poor engagement with services as indicated by an unclear treatment history, poor adherence, increasing seizure frequency and subtherapeutic medication levels increased the risk of being in the SUDEP group. As previously found if patients misuse alcohol, they add to their risk of SUDEP. If patients have night surveillance through someone sleeping with them or using a monitor, risk is reduced, as is sleeping in the non-prone position. While the association of the 'prone position' is strong and theoretically a modifiable risk factor the actual and practical modifiability of this factor is contested. People do not typically stay just prone in bed, while sleeping they toss and turn. Patients with epilepsy typically roll over when having seizures to turn their face into the pillow. There might be a role for anti-asphyxia pillows [14]. Night surveillance, while a practically achievable issue, should take into account privacy issues and the choice to live alone. A practical person-centered approach to such social situations might pay dividends. All of these factors can be addressed but require the patient to be informed about SUDEP risks (an aim of the SUDEP checklist).

As with the combined analysis [9] carbamazepine as a risk factor was not significant thus further consolidating its safety profile with regard to SUDEP. Interestingly being male and taking antidepressants were not significant; this may have been the result of an underpowered study but it does indicate that these factors are probably not so critical.

The negative finding on intellectual disability (ID) is difficult to interpret. Other studies have shown this to be a risk factor of SUDEP [9, 10, 15, 16]. However, Cornwall has a dedicated ID epilepsy service as approximately $25 \%$ of PWE have ID and our data suggest only $6.3 \%$ of people dying from SUDEP have an ID [4] compared to $23.4 \%$ in other studies [15]. It is possible that ID as a risk factor is dependent on the quality of services rather than the ID itself.

There are clear limitations to this study. The cases of people dying from SUDEP were taken over 9 years between 2004 and 2012. The controls were patients attending specialist clinics between 2013 and 2014. However, the management of epilepsy has not changed radically over this period as reflected in the similar NICE guidelines for the management of epilepsy published in 2004 and 2012. The 1st line drugs and many other strategies for managing seizures remain pretty much the same. In spite of being proposed as a NICE guidance since 2004 the communication of the risk of SUDEP has been significantly low in fact $4 \%$ in 2013 [17]. Both the 2001 and 2011 national census confirms Cornwall is one of the poorest parts of the United Kingdom in terms of per capita GDP and average household incomes. They also reveal social deprivation, ethnicity and migration rates (very low) have not changed substantially. In fact, the same epilepsy teams and personnel have been in place managing this same population of PWE which has a low turnover. While all the controls were from specialist clinics it is worth noting that the highest risk patients were being compared. It can be thus argued that the impact of the potential bias of the various limitations emerging from the control group selection is minimal.

Given that subtherapeutic drug levels may be a reflection of medication nonadherence, the two are by no means independent of each other. The same is true for early onset of epilepsy and prolonged ( $>15$ years) duration of epilepsy not necessarily mutually exclusive. Unfortunately, given low numbers and missing data a logistic regression analysis could not be performed.

The cases and controls were not matched samples. The review of medical notes was not blind to the reviewers which may be a source of bias, and the controls were determined from outpatient clinics. However, this is the first study where a structured application of a pre-designed risk checklist to both the demised PWE and controls has been done. Both sets were also drawn from the same at risk epidemiological population, i.e., county of Cornwall (population 550,000) UK. This has provided an opportunity to rank the risk factors thus highlighting that SUDEP is not only modifiable and multidimensional but likely to be associated with different intensity and degrees of risk. It again highlights that SUDEP could be a cumulative effect of few or many of these risk factors, many modifiable and possibly coming together in a 'perfect storm' to cause an adverse outcome. There were two children under 15 in the study. Some factors would not apply to children and others might be less modifiable. Given the small numbers we do not believe it would have influenced the outcome of our study.

Overall, our study supports the use of an evidenced based checklist to discuss potentially modifiable factors with patients, especially to inform people of their person centred risk of SUDEP. Cornwall Public Health and coroner annual data show SUDEP deaths have reduced 
considerably in the last 2 years compared to previous years, though given the small numbers involved and the multiple variables these at best are early trends. It sits well with the fact that of PWE and/or their carers administered the checklist in the last 3 years in epilepsy clinics $(n=400+)$ in Cornwall UK, $98 \%$ of patients approved, felt empowered and felt safer knowing person-centered risk $[5,6]$. There is anecdotal evidence to suggest it contributed to improved compliance and adherence of medication and more importantly contact with health services if problems existed with the medication as opposed to generally stopping it without advice. A structured approach may pay dividends in focusing individuals on items in their locus of control and may mitigate risk.

Acknowledgments Professor Torbjorn Tomson Department of Clinical Neuroscience, Karolinska Institutet, Stockholm, Sweden.

\section{Compliance with ethical standards}

Conflicts of interest JH, CN, FF, and RL report no conflicts. RS has received institutional and research support and personal fees from UCB, Eisai, Janssen, Lilly, GSK, Servier, Astra Zeneca and Desitin outside the submitted work. MW has received institutional and personal fees from Eisai and $\mathrm{UCB}$. BMcL has received research support and personal fees from Eisai, UCB, GSK and Desitin outside the current work.

Ethical standards All procedures involved in this study involving human participants were in accordance with the institutional and national research committees and with the 1964 Helsinki declaration and its later amendments. For this retrospective study formal consenting was not required.

\section{References}

1. Duncan JS, Sander JW, Sisodiya SM et al (2006) Adult epilepsy. Lancet 367:1087-1100

2. Tellez-Zenteno JF, Hern'andez Ronquillo L, Wiebe S (2005) Sudden unexpected death in epilepsy: evidence-based analysis of incidence and risk factors. Epilepsy Res 65:101-115
3. Shankar R, Cox D, Jalihal V et al (2013) Sudden unexpected death in epilepsy (SUDEP): development of a safety checklist. Seizure 22(10):812-817

4. Shankar R, Jalihal V, Walker M et al (2014) A community study in Cornwall UK of sudden unexpected death in epilepsy (SUDEP) in a 9-year population sample. Seizure 23(5):382-385

5. Shankar R, Newman C, McLean B, Anderson T (2015) Can technology help reduce risk of harm in patients with epilepsy? $\mathrm{Br}$ J Gen Pract 65(638):448-449

6. Shankar R, Newman C, Hanna J, Ashton J, Jory C, McLean B, Anderson T, Walker M, Cox D, Ewins L (2015) Keeping patients with epilepsy safe: a surmountable challenge? BMJ Qual Improv Rep. doi:10.1136/bmjquality.u208167.w3252

7. https://www.sudep.org/checklist. Accessed 16 Apr 2016

8. Annegers JF, Coan SP (1999) SUDEP: overview of definitions and review of incidence data. Seizure 8(6):347-352

9. Hesdorffer DC, Tomson T, Benn E et al (2011) Commission on Epidemiology. Subcommission on mortality combined analysis of risk factors for SUDEP. Epilepsia. 52(6):1150-1159

10. Walczak TS, Leppik IE, D'Amelio M et al (2001) Incidence and risk factors in sudden unexplained death in epilepsy: a prospective cohort study. Neurology 56:519-525

11. Langan Y, Nashef L, Sander JW (2005) Case-control study of SUDEP. Neurology 64:1131-1133

12. Hitiris N, Suratman S, Kelly K et al (2007) Sudden unexpected death in epilepsy: a search for risk factors. Epilepsy Behav 10:138-141

13. Nilsson L, Farahmand BY, Persson P et al (1999) Risk factors for sudden unexpected death in epilepsy: a case control study. Lancet 353:888-893

14. Catcheside P, Mohtar A, Reynolds K et al (2014) Airflow resistance and $\mathrm{CO} 2$ rebreathing properties of anti-asphyxia pillows designed for epilepsy. Seizure Eur J Epilepsy 23(6):462-467

15. Young C, Shankar R, Palmer J et al (2015) Does intellectual disability increase sudden unexpected death in epilepsy (SUDEP) risk. Seizure 25:112-116

16. Kiani R, Tyrer F, Jesu A et al (2013) Mortality from sudden unexpected death in epilepsy (SUDEP) in a cohort of adults with intellectual disability. J Intellect Disabil Res 58(6):508-520

17. Waddell B, McColl K, Turner C et al (2013) Are we discussing SUDEP? A retrospective case note analysis. Seizure Eur J Epilepsy 22(1):74-76

18. Tomson T, Surges R, Delamont R et al (2016) Who to target in sudden unexpected death in epilepsy prevention and how? Risk factors, biomarkers, and intervention study designs. Epilepsia 57(Suppl. 1):4-16 